\title{
Comparison between Electrospun and Bubbfil-spun Polyether Sulfone Fibers
}

\author{
$\mathrm{Ya} \mathrm{Li}^{1,2}$, Rou-xi Chen ${ }^{1,2}$, \\ Fu-Juan $\mathrm{Liu}^{1,2}$
}

\author{
${ }^{1}$ National Engineering Laboratory for Modern Silk, College of Textile and Clothing Engineering, Soochow \\ University, 199 Ren-Ai Road, Suzhou, China \\ ${ }^{2}$ Nantong Textile Institute, Soochow University, Nantong, China \\ e-mail: liufujuan@suda.edu.cn
}

\begin{abstract}
Electrospinning is a simple method for producing ultrafine fibers, and has attracted much recent interest. The classical approach was either polymer solutions or polymer melts. Bubbfil spinning (e.g. bubble-electrospinning) is a facile method to fabricate nanofibers with high surface area to volume ratio and high porosity. Polyether sulfone (PES) dissolved in N,N-Dimethylacetamide (DMAC) was used in this study to compare fiber morphologies of two technologies at the same spinning conditions. Effects of solution concentration, applied voltage and tip-to-collector distance on the morphology of the fibers were experimentally studied. It revealed that the Bubbfil spinning process is a better candidate for mass-production of nanofiber with controllable morphology.
\end{abstract}

Keywords: Electrospinning, Bubble-electrospinning, difference, porous morphology.

\section{INTRODUCTION}

The electrospinning process, invented by Formhals in 1934 [1], was widely studied on the whole world during the last decades $[2,3]$. It has been found that the fiber diameter can be controlled within a broad range down to a few tens of nanometers by proper selection of the processing parameters [2]. Recently a new approach was invented using polymer bubbles, which is a potential technology for mass-production of nano/micro-fibers, and it is termed as Bubbfil spinning technology [4].

Bubbfil spinning [4]] is developed from the bubble-electrospinning [ [, $\underline{6}, 7]$, blown-bubble spinning [ [ $]$, and membrane spinning $[9,10]$, it is use electronic force, blowing air, or other forces to overcome the surface tension of a bubble or a membrane. The bubble electrospinning was first invented in 2007 by Ji-Huan He and his collogues (Chinese patent ZLGL2007030001). After several years' improvement, the technology has been more and more matured.

Polyether sulfone (PES) has good chemical properties and hydrolysis stability, high strength, a wide $\mathrm{pH}$ range from 1 to 13 . In addition, the highest working temperature can reach $129{ }^{\circ} \mathrm{C}$, and it has good oxidation resistance and resistance to chloride, therefore, it has become one of important membrane materials. The fiber membrane obtained either electrospinning or Bubbfil spinning has light quality, good permeability, large specific surface, high porosity and good internal pore connectivity, being good filtering material $[11,12,13]$. In the study, the author used $\mathrm{N}, \mathrm{N}$-Dimethylacetamide (DMAC) to dissolve PES for electrospinning and Bubbfil spinning.

\section{WORKING PRINCIPLE AND TECHNOLOGICAL PROCESS}

The principle of electrospinning is shown in Fig. 1. The polymer solution or melt with high voltage results in charged polymer droplet under the force of electric field in which the Taylor cone is formed. When the electric field force is big enough to overcome the surface tension of Taylor cone, a moving jet is ejected. In this process of injection, the jet is solidified into fiber after solvent evaporation. 
Figure. 2 gives a bubble electrospinning set up. Bubbles are produced by a controllable syringe pump, and number of bubbles depends upon the size of tube. The number of bubbles reduces with decrease of the diameter of the tube, when the tube reduces to a threshold value, only a single bubble is formed. The voltage is applied to overcome the surface tensions of bubbles, when the voltage reaches a threshold, multiple jets are ejected from bubbles. After the bubble burst to debris, under non-uniform electric field or flow field, they further stretches to form fibers. A metal receiver above is used for collecting fibers. Bubble-spinning is to overcome the surface tension of the bubble to complete the spinning process, in which its surface tension has nothing to do with the nature of the solution as that in Taylor cone, and is only affected by the size of the bubbles and the gas pressure difference between inside and outside of the bubble.

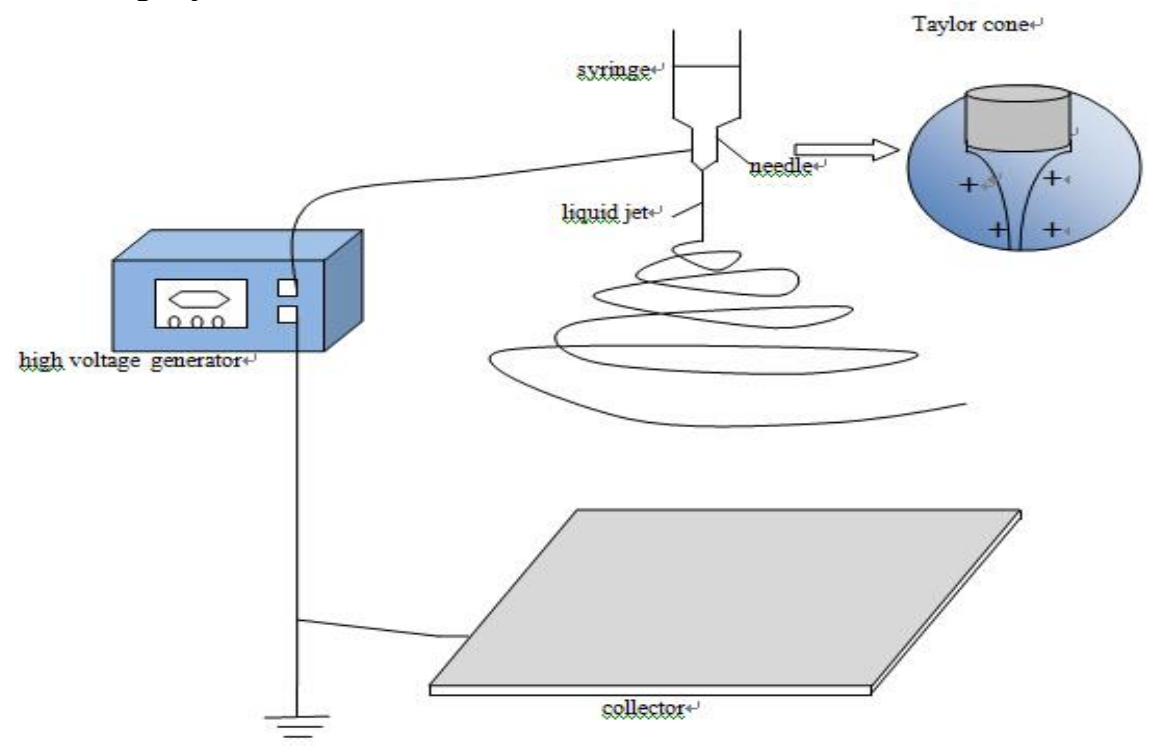

Figure 1: Traditional electrospinning device

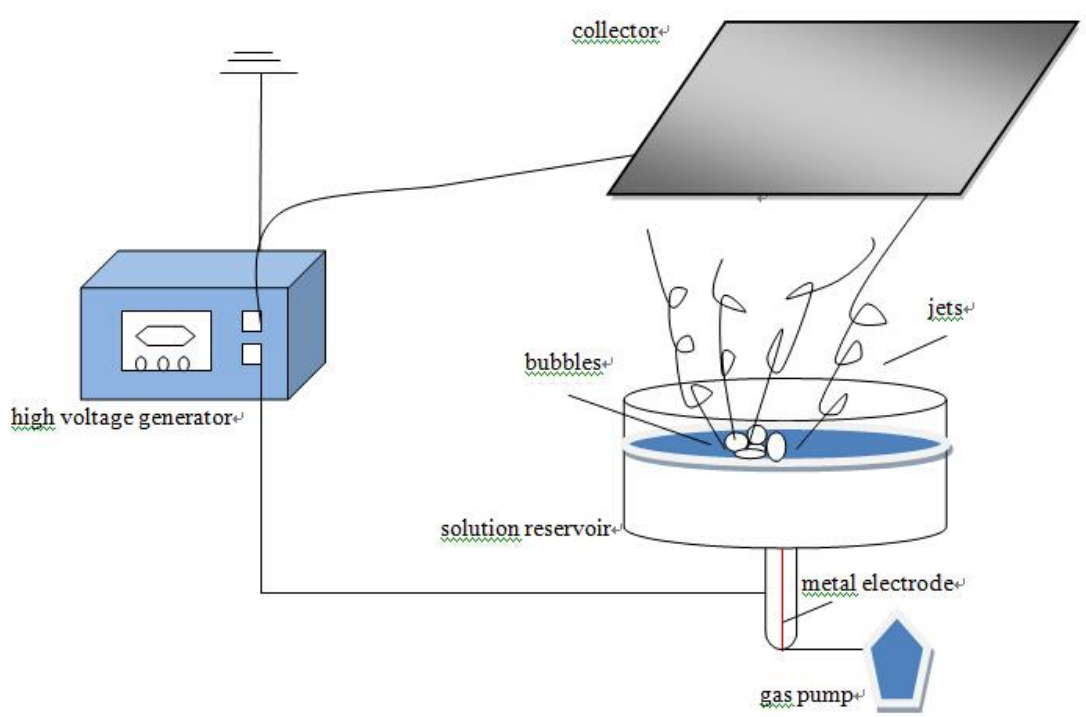

Figure 2: Device for bubble-electrospinning

\section{EXPERIMENT AL PROCEDUR}

The Polyether sulfone material was purchased from American SOLVAY and the pure N, N dimethyl acetamide was produced from the United States Dupont Chemical Group Co., LTD. A variable high voltage power supply was used to produce voltages ranging from 0 to $50 \mathrm{kV}$. The indoor humidity is kept at $40 \% \mathrm{RH}$, and all spinning conditions are kept same for comparison of the two technologies. 
Considering the control factors in the process of spinning, whether traditional or bubble-electrospinning, three parameters of solution concentration, applied voltage and tip-to-collector distance were meaningful and studied here. The applied voltage was increased gradually from $15 \mathrm{kv}, 20 \mathrm{kv}$, to $25 \mathrm{kv}$. The polymer concentrations $25 \mathrm{wt} \%$ and $30 \mathrm{wt} \%$, respectively, and the tip-to-collector distances in the experiment were set as $10 \mathrm{~cm}$ and $15 \mathrm{~cm}$, respectively. The samples collected were placed in a vacuum oven for $24 \mathrm{~h}$ at room temperature in order to remove the solvent residuals.

\section{RESULTS AND DISCUSSION}

The morphology of the fibers was examined with scanning electron microscopy (SEM, GSM-5900, Jeol. Co., Japan). The diameter and distribution of the bead were obtained by using image analyzer. The results are given in Figure 3 and Figure 4 at diffenerent spinning conditions.

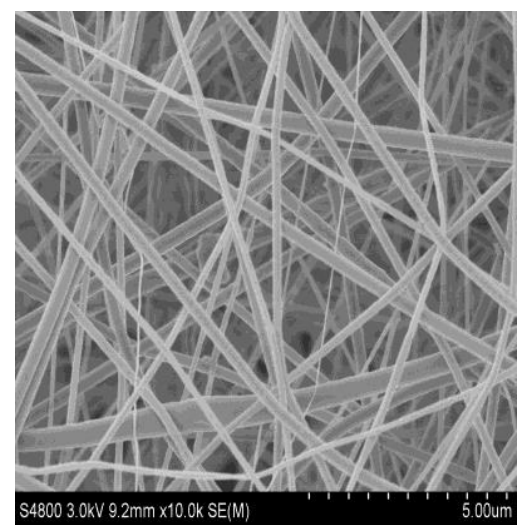

(a) $25 \% \quad 15 \mathrm{kv} \quad 10 \mathrm{~cm}$

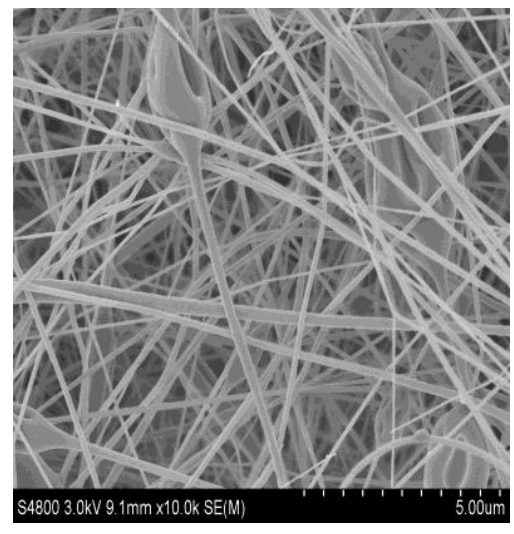

(d) $25 \% \quad 15 \mathrm{kv} \quad 15 \mathrm{~cm}$

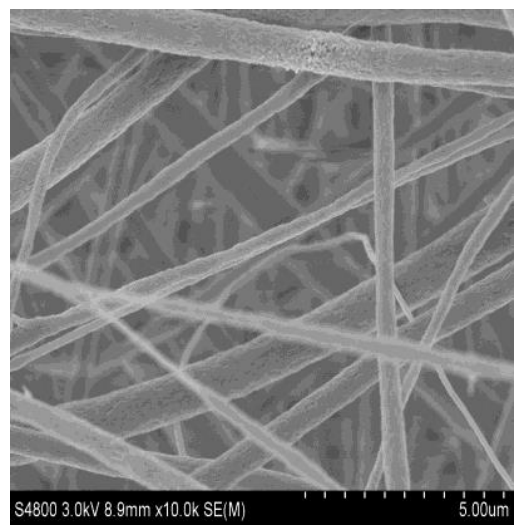

(h) $30 \% \quad 15 \mathrm{kv} \quad 10 \mathrm{~cm}$

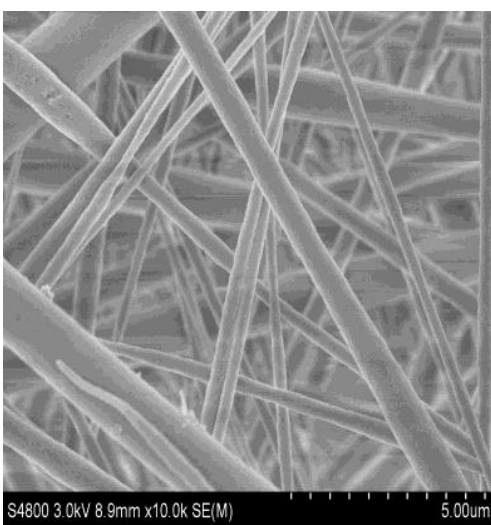

(b) $25 \% 20 \mathrm{kv} \quad 10 \mathrm{~cm}$

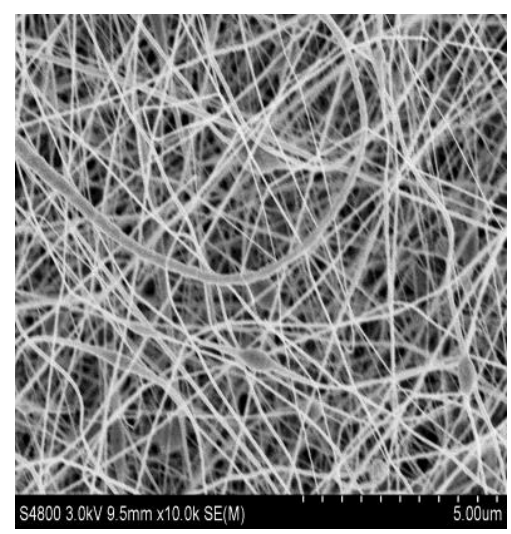

(e) $25 \% 20 \mathrm{kv} \quad 15 \mathrm{~cm}$

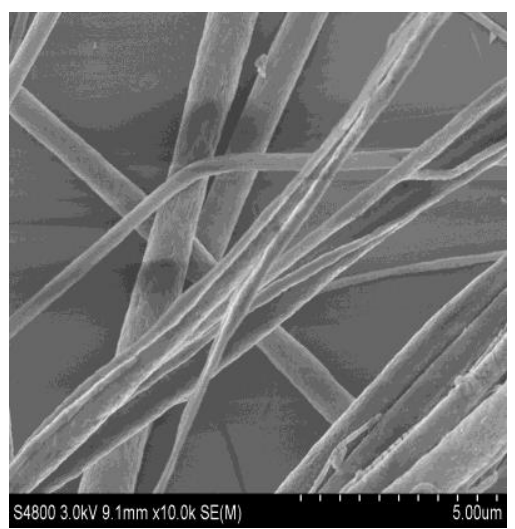

(i) $30 \% 20 \mathrm{kv} \quad 10 \mathrm{~cm}$

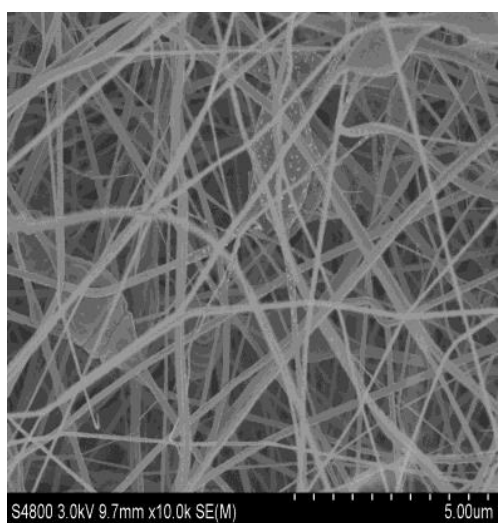

(c) $25 \% 25 \mathrm{kv} 10 \mathrm{~cm}$

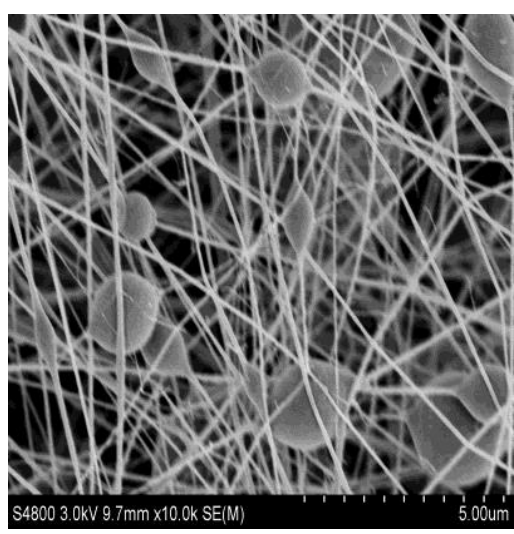

(f) $25 \% 25 \mathrm{kv} 15 \mathrm{~cm}$

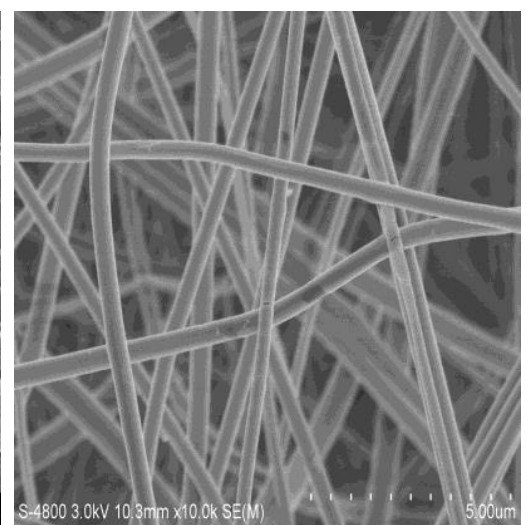

(j) $30 \% 25 \mathrm{kv} 10 \mathrm{~cm}$ 


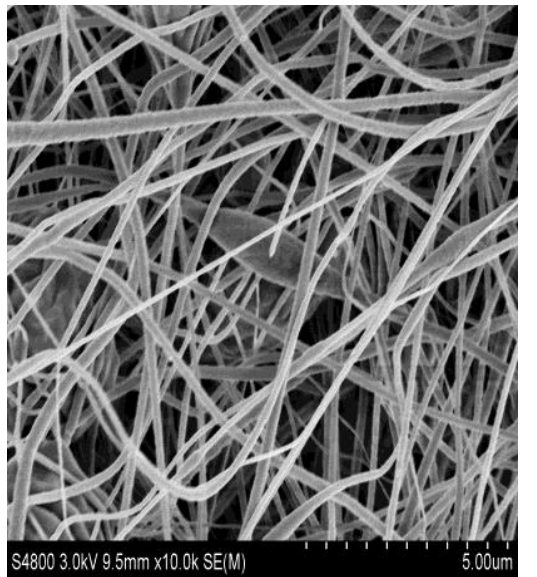

(k) $30 \% \quad 15 \mathrm{kv} \quad 15 \mathrm{~cm}$

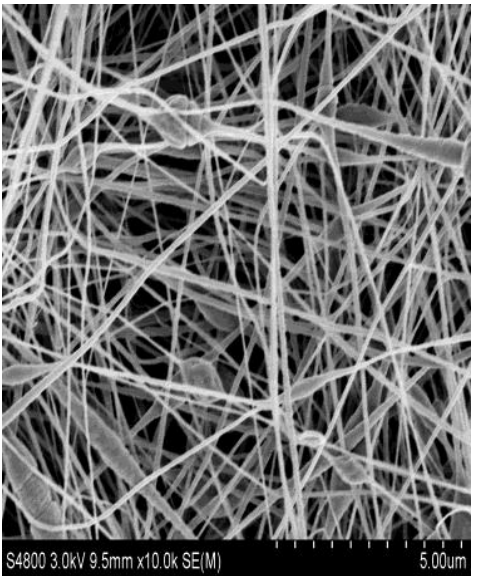

(l) $30 \% 20 \mathrm{kv} \quad 15 \mathrm{~cm}$

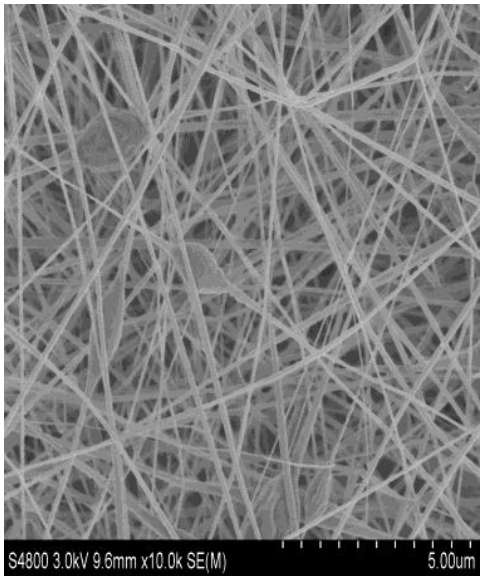

(m) $30 \% 25 \mathrm{kv} 15 \mathrm{~cm}$

Figure 3: SEM images of PES/DMAC membranes fabricated by electrospinning at different solution concentrations, applied voltage, and tip-to-collector distances

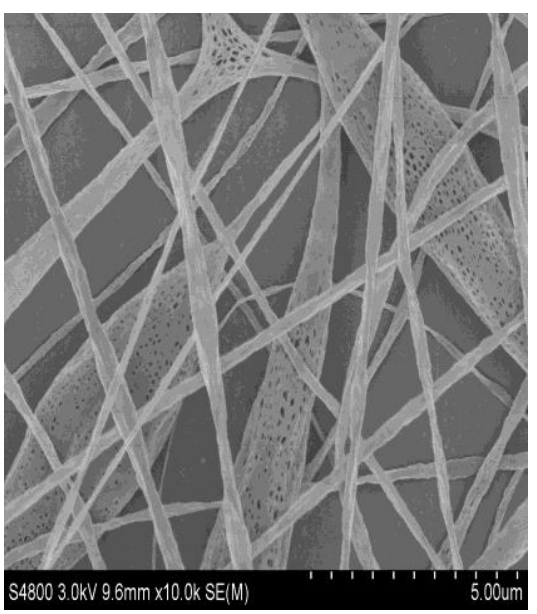

(a) $25 \% \quad 15 \mathrm{kv} \quad 10 \mathrm{~cm}$

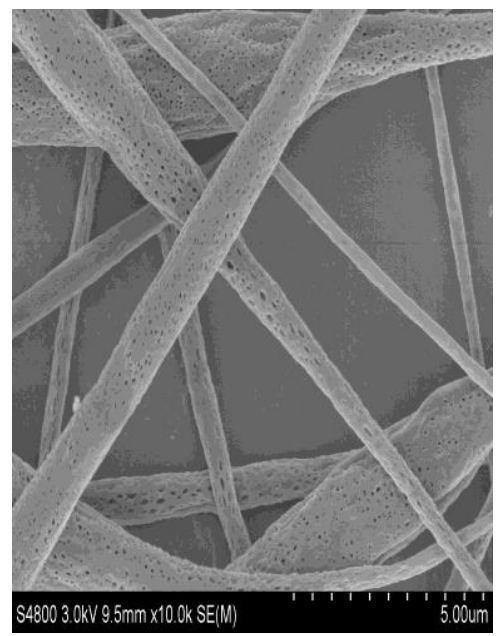

(d) $25 \% 15 \mathrm{kv} 15 \mathrm{~cm}$

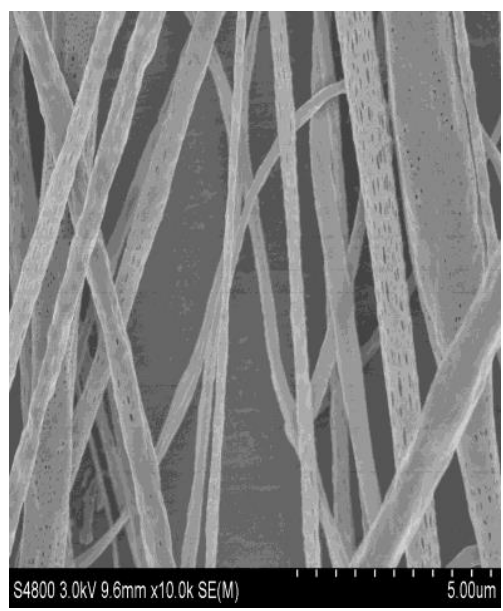

(b) $25 \% 20 \mathrm{kv} \quad 10 \mathrm{~cm}$

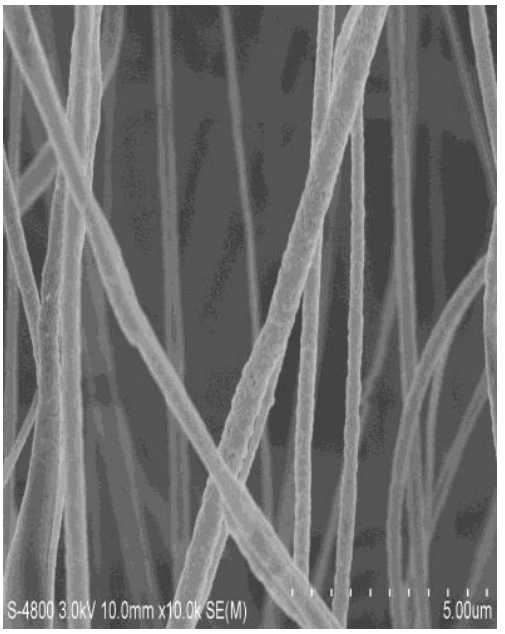

(e) $25 \% 20 \mathrm{kv} 15 \mathrm{~cm}$

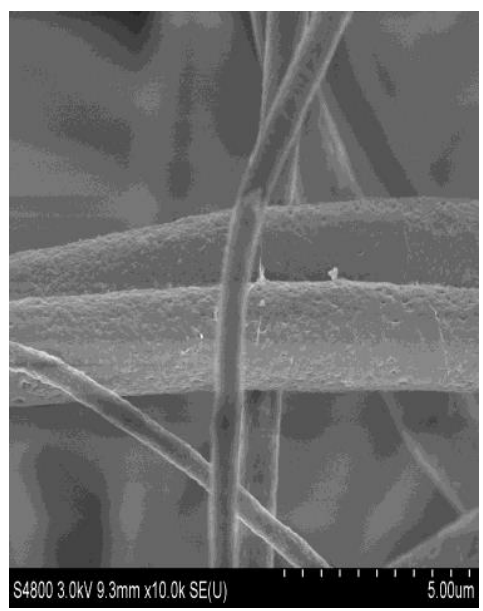

(c) $25 \% 25 \mathrm{kv} 10 \mathrm{~cm}$

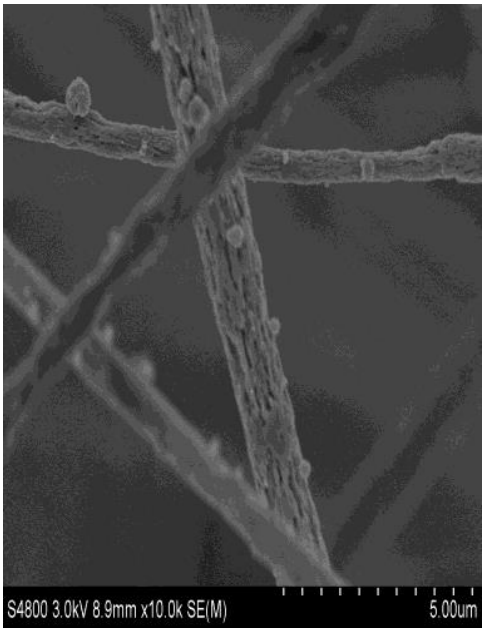

(f) $25 \% 25 \mathrm{kv} 15 \mathrm{~cm}$ 


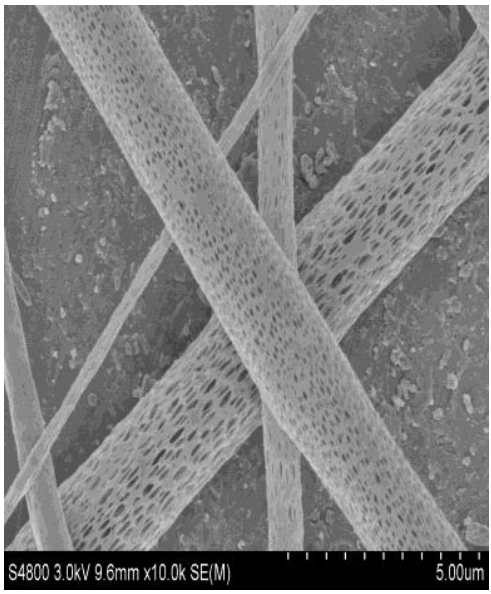

(h) $30 \% 15 \mathrm{kv} 10 \mathrm{~cm}$

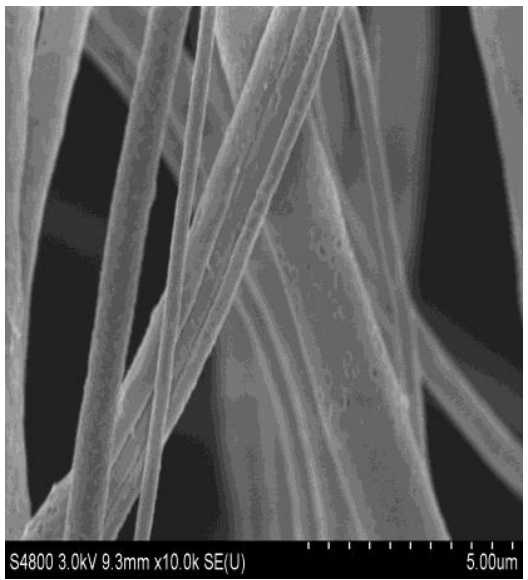

(k) $30 \% 15 \mathrm{kv} 15 \mathrm{~cm}$

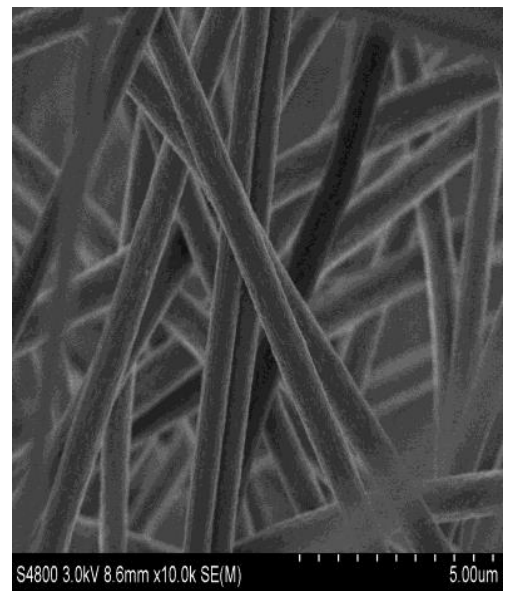

(i) $30 \% 20 \mathrm{kv} 10 \mathrm{~cm}$

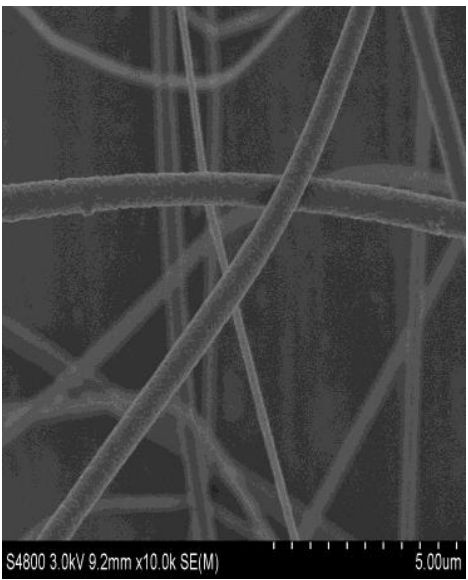

(l) $30 \% 20 \mathrm{kv} 15 \mathrm{~cm}$

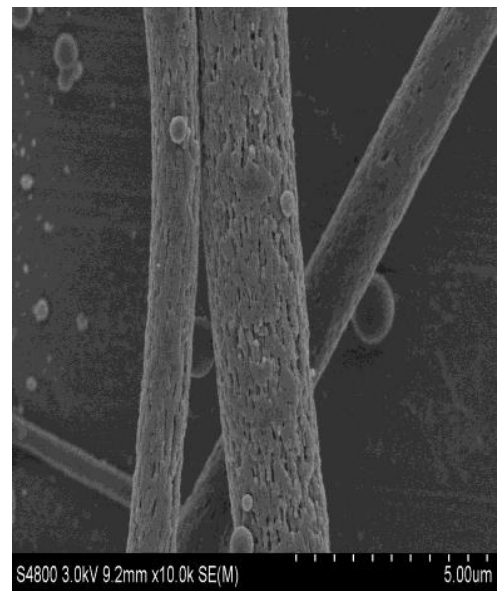

(j) $30 \% 25 \mathrm{kv} 10 \mathrm{~cm}$

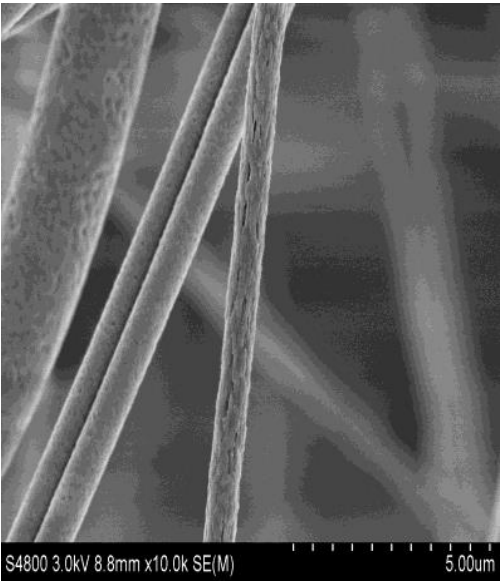

(m) $30 \% 25 \mathrm{kv} 15 \mathrm{~cm}$

Figure 4: SEM images of PES/DMAC membranes fabricated by bubble-electrospinning at the same spinning parameters as electrospinning

The change of bead morphology and nanofiber morphology is shown in Figure 3 and Figure 4. Through a series of experiments, in traditional electrospinning if PES concentration was lower than $16 \mathrm{wt} \%$, then small droplets appeared. In the process of increasing the concentration, although it could not completely rule out the emergence of small droplets, electrospinning effect was becoming more and more stable. When the PES concentration was higher than $35 \mathrm{wt} \%$, it could not be used for spinning due to condensate easily, either. Similarly, the threshold values for Bubbfil spinning were $20 \mathrm{wt} \%$ and $38 \mathrm{wt} \%$.

In both of the electrospinning and the bubble-electrospinning, the change trend of bead morphology and nanofiber morphology is the same as shown in Fig.5 and Fig.6. With increasing concentration, the diameter of bead became smaller while that of nanofiber showed a trend of increase. On the contrary, the diameter of bead became bigger, but showed a trend of decrease about nanofiber when the tip to collector distances were enlarged. The shape of the droplet at the syringe tip and the continuous fragment resulted from the bubbles can be changed by the intensity of the applied voltage and the resulting morphology and aspect ratio became smaller and then larger. Overall, the aspect ratio increased first and then decreased with the applied voltage, with this transition occurring at a midpoint voltage.

However, the morphology of fibers got at the two spinning methods had a main difference. The nanofibers made by electrospinning tend to be smooth mostly while what got from bubble-electrospinning were all porous nanofibers as shown in Fig.4. 

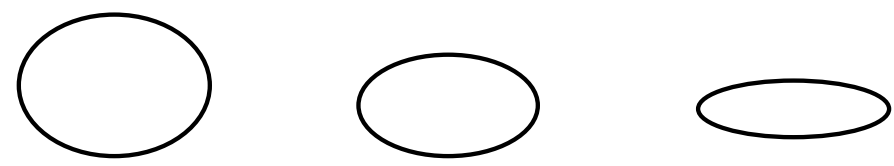

(a) Increasing concentration
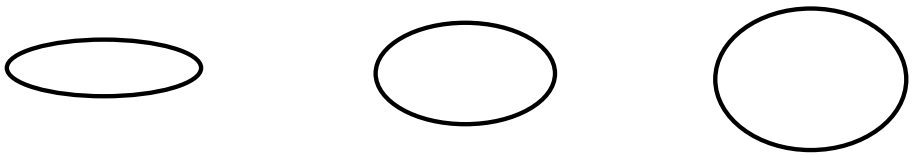

(b)Increasing tip-to-collector distance
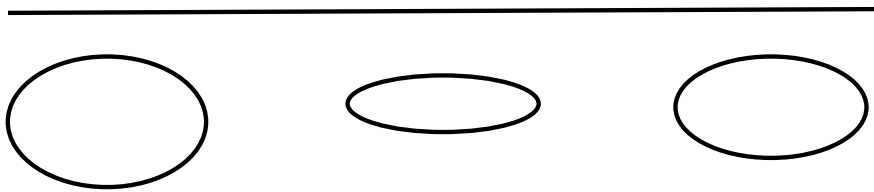

(c)Increasing voltage

Figure 5: The change of bead morphology in the electrospinning and bubble-electrospinning
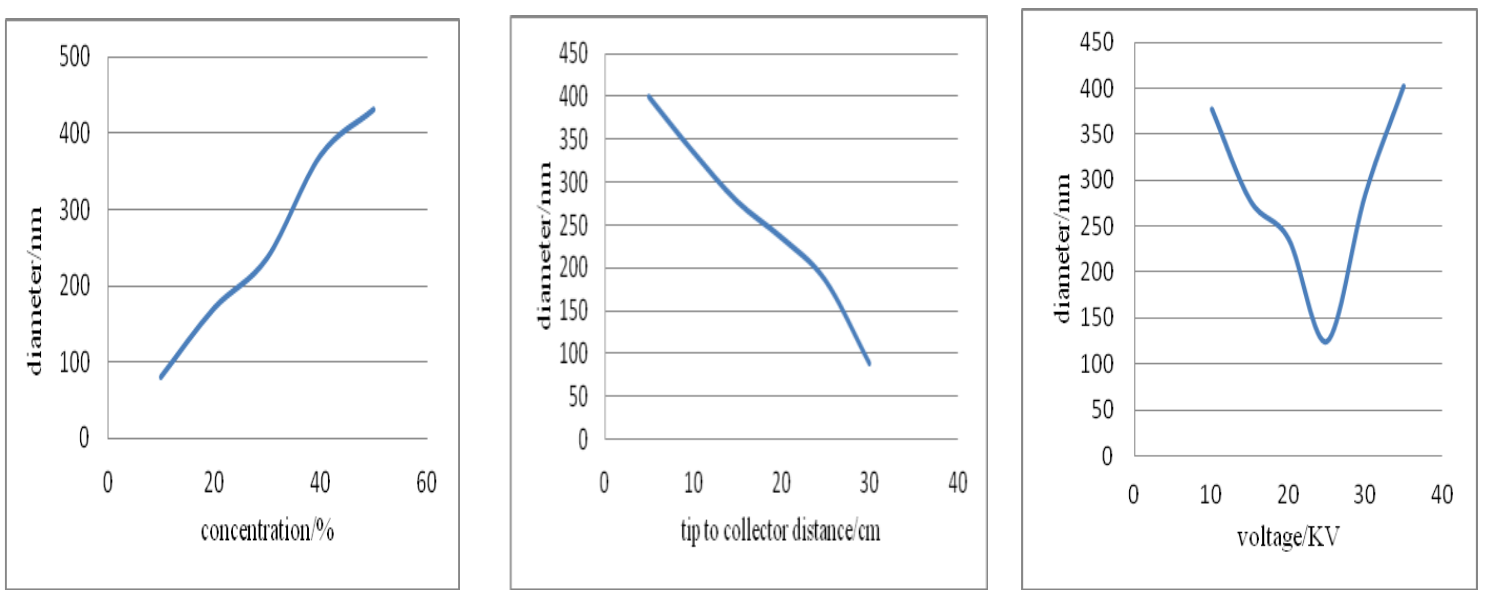

Figure 6: The change of nanofiber morphology in electrospinning and bubble-electrospinning

\section{CONCLUSIONS}

The working principles of the two methods are totally different, as a result the morphologies of the fibers diverge greatly even though the change trend of bead morphology and nanofiber morphology formed on either electrospun or bubble-electrospun polystyrene fibers is the same. The main advantages of the Bubbfil spinning is the high throughout for industrial applications and porous fibers for many potential applications in various fields especially in filtration.

\section{ACKNOWLEDGEMENT}

The work is supported by Priority Academic Program Development of Jiangsu Higher Education Institutions (PAPD), National Natural Science Foundation of China under grant No.11372205, No. 51403143 and Project for Six Kinds of Top Talents in Jiangsu Province under grant No.ZBZZ-035, Science \& Technology Pillar Program of Jiangsu Province under grant No.BE2013072, Research and Innovation Project for College Graduates of Jiangsu Province under grant No. CXZZ13-0817, Jiangsu Province Key Laboratory No.KJS1314 and Jiangsu Planned Projects for Postdoctoral Research Funds1401076B, Natural Science Foundation of Jiangsu Province (Grant No. BK20140398), China Postdoctoral Science Foundation (Grant No. 2014M551658), Postdoctoral Research funding plan of Jiangsu Province (Grant No. 1302101B). 


\section{BIBLIOGRAPHY}

[1] FORMHALS, A., US Patent 1-975-504, 1934.

[2] DOSHIi, J., "The elecrospinning process and applications of electrospun fibers”, Thesis, Akron, 1994.

[3] WANG, P., HE, J.H. "Electrospun polyvinyl alcohol-honey nanofibers", Thermal Science, V. 17, n. 5, pp. 1549-1550, 2013.

[4]HE,J.H., KONG,H.Y., et al. "Variational iteration method for Bratu-like equation arising in electrospinning", Carbohydrate polymer, v.105, pp.229-230, 2014

[5] He, J.H., KONG, H.Y., YANG, R.R., et al., "Review on fiber morphology obtained by bubble electrospinning and blown bubble spinning", Thermal Science, v.16, N.5,1263-1279, 2012.

[6]LIU,F.J., DOU, H. "A modified Young-Laplace equation for the bubble electrospinning considering the effect of humidity", Thermal Science, v. 17, n. 5, pp. 629-630, 2013

[7] DOU, H., LIU, H.Y., et al. "A belt-like superfine film fabricated by bubble-electrospinning", Thermal Science, v. 17, n. 5, pp. 1508-1510, 2013

[8]DOU,H., LIU, H.Y., MO,L.F.,'Blown bubble-spinning and micro yarns", Bubbfil Nanotechnology, v. 1, n.1, pp. 24-28, 2014

[9] KONG, H.Y., He, J.H., et al., "Polymer liquid membrane for nanofiber fabrication", Thermal Science, V. 17 , n. 5, pp. 1479-1482, 2013

[10] KONG, H.Y., HE, J.H., "A modified bubble electrospinning for fabrication of nanofibers", Journal of Nano Research, v. 23, pp. 125-128, 2013.

[11]CHEN, R.X., ZHANF,L., et al., "Mechanism of nanofiber crimp", Thermal Science, v. 17, n. 5, pp. 1473-1477, 2013

[12] BARHATE, R.S., LOONG, C.K., et al., "Preparation and characterization of nanofibrous filtering media", J. Membr Sci, v. 283, n 1/2, pp. 209-218, 2006.

[13] GOPAL, R., KAUR, S., et al., "Electrospun nanofibrous filtration membrane", J. Membr Sci, v.281, n 1/2, pp. 581-586, 2006. 